\title{
Mapping 20 Years of Literature on CSR in Tourism Industry: A Bibliometric Analysis
}

\author{
Fatima Ezzahra Jiddi*, Abdelmajid Ibenrissoul \\ Laboratory of Scientific Engineering of Organizations (ISO), National School of Business and Management (ENCG-Casa), \\ University Hassan II, Casablanca, Morocco \\ Email: `jiddi.fz@gmail.com
}

How to cite this paper: Jiddi, F. E., \& Ibenrissoul, A. (2020). Mapping 20 Years of Literature on CSR in Tourism Industry: A Bibliometric Analysis. American Journal of Industrial and Business Management, 10, 1739-1759.

https://doi.org/10.4236/ajibm.2020.1011109

Received: October 31, 2020

Accepted: November 27, 2020

Published: November 30, 2020

Copyright (c) 2020 by author(s) and Scientific Research Publishing Inc. This work is licensed under the Creative Commons Attribution International License (CC BY 4.0).

http://creativecommons.org/licenses/by/4.0/

\begin{abstract}
The tourism industry has a tremendous impact on the environment and local communities. Therefore, corporate social responsibility (CSR) is essential both as a mediating factor and competitive edge for organizations in this field. This paper reviews CSR in the tourism industry and proposes a bibliometric analysis of 131 indexed articles, between 2001 and 2020. The most influential aspects of the literature (authors, articles, journals, institutions, and keyword networks) were identified. Co-citation analysis combined with content analysis of the 22 most cited articles was performed, and four research streams were revealed: 1) CSR and financial performance; 2) CSR practices, drivers, and inhibitors; 3) Reporting and communication of CSR; 4) CSR and stakeholder behavior. Future research guidelines are drawn from the most recent articles on this topic to shed new light for the future scholars working in the field.
\end{abstract}

\section{Keywords}

Corporate Social Responsibility, Tourism, Literature Review, Bibliometric Analysis, Content Analysis

\section{Introduction}

The COVID-19 pandemic has had significant repercussions on the global economy. The tourism industry has been the worst affected (UNWTO, 2020). According to the World Tourism Organization, 100 to 120 million jobs are at risk and businesses involving up to 1.1 billion international tourists have been lost. In other words, up to US\$ 1.2 trillion in export revenues from tourism has been lost. Dodds \& Kuehnel (2010) found that tour operators recognized pandemics, among others, as the main threat for the tourism sector. 
As such, corporate social responsibility (CSR) has an impact on all stakeholders, including the community. In the tourism industry, CSR takes the form of room night donations, restaurant contributions, charitable contributions, and others. Examining CSR is particularly relevant in the tourism industry because of the sector's contribution to environmental issues, such as air pollution, global warming, and littering (Bohdanowicz, 2003). Such environmental issues can be advantageous for socially responsible companies in term of eco-savings, enhanced product quality, increased market share, employee and customer satisfaction and improved relationships within the community (Garay \& Font, 2012).

Despite the centrality of CSR in the tourism industry, little research has been carried out in this area. A few tourism academics have explored the subject considerably and systematically, which results in a partial body of knowledge (Coles et al., 2013). It is therefore crucial to compile the richness of literature in this topic systematically and specifically limit it to CSR. In this context, this study, based on a literature analysis of 20 years (Figure 1), aims to analyze thoroughly the commonly reviewed research themes relating to CSR in the tourism industry. Figure 1 shows that the literature on CSR in the tourism industry has started to receive attention since 2001 and has evolved since. The year 2019 received the highest number of publications and the year 2013 received the most citations globally.

A bibliometric review, considered as the most suitable analysis in our case, addresses the following questions: 1) What are the most leading attributes of literature such as journals, authors, articles, countries, and institutions? 2) What are the keywords used, and what is the network among them in the literature of all the articles studied? 3) What are the main clusters in the literature of CSR in the tourism industry? 4) What are the relevant future research questions extracted from the trending articles in the literature? To answer the stated questions, a synopsis of the most influential aspects of the literature was summarized in Section 1 titled "Descriptive Analysis". Section 2 reviewed "Keywords Network Analysis", and the research streams based on a quali-quantitative analysis

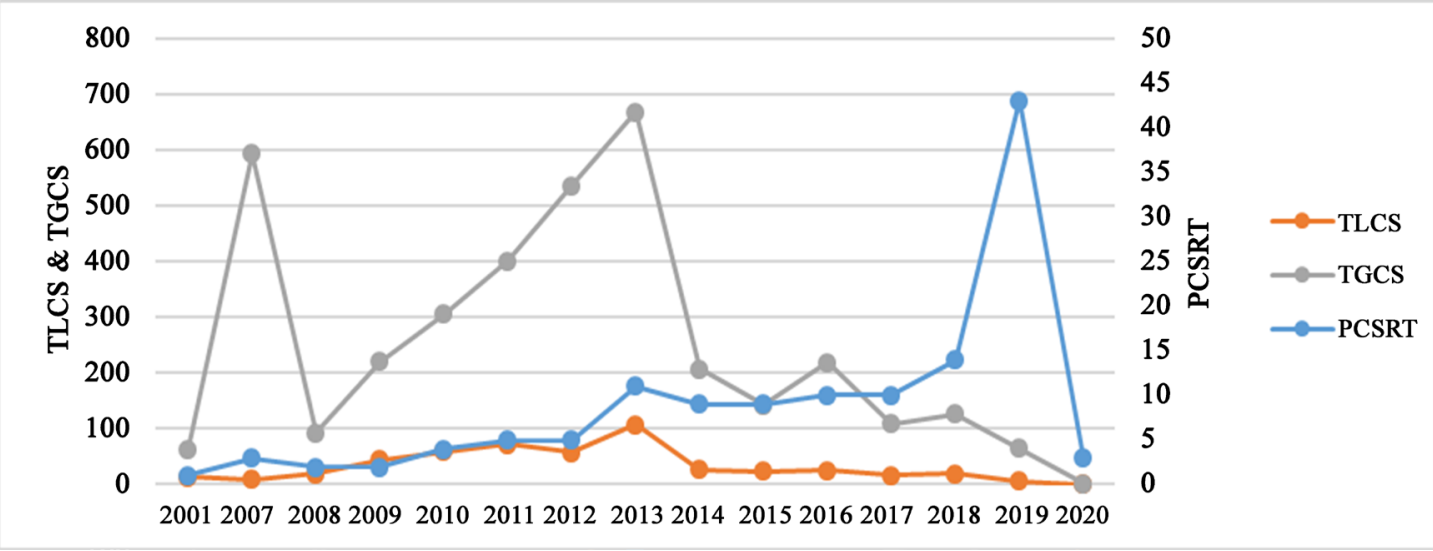

Note: For more details about TLCS, TGCS, PCSRT see Table 2.

Figure 1. Evolution of number of publications and citations. 
are presented in Section 3 "Cluster Analysis". Finally, the "Future Research Questions” were identified in Section 4.

\section{Methodology}

Figure 2 summarizes the methodology used in this study.

\subsection{Data Collection Method}

The search for related articles was made on ISI Web of Science (ISI WOS), an indexed database that scholars use to perform a bibliometric research (Nova-Reyes et al., 2020; Rodrigues \& Mendes, 2018; Lulewicz-Sas, 2017). To identify only relevant papers, the search process was conducted using the following rigorous four-step approach.

- The search in the "topic" section included titles of articles, abstracts and keywords and was defined by two keywords "corporate social responsibility" and "tourism" (456). The search was then restricted to only scientific articles written in English (326).

- The categories were limited to "hospitality leisure sport tourism", "management", "economics", "business", "ethics", "green sustainable science technology," and "environmental studies and sciences." Accordingly, the ISI WOS research areas of social sciences: business economics and environmental (305) were selected.

- To keep the study focused and limit bias in our analysis, the search was specifically limited to CSR rather than related terms such as sustainable development, sustainable tourism, and greenwashing. Emphasis was also placed

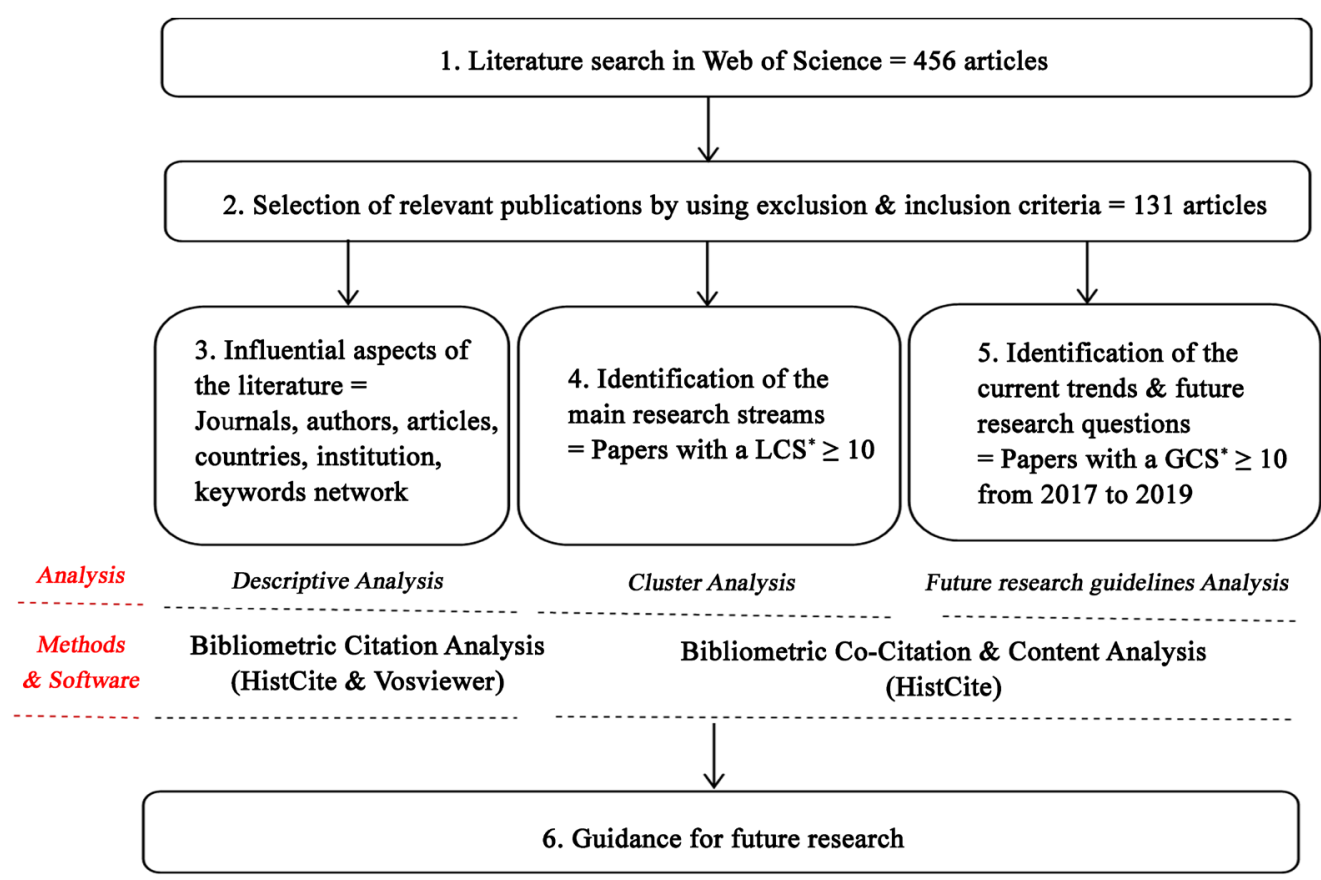

"For more details about LCS and GCS see Table 2.

Figure 2. Research methodology. 
on articles with an explicit reference to our research topic, and thus we excluded, for example, articles referring to one component of CSR such as philanthropy or stakeholders in the tourism industry. The data collected were then analyzed by reviewing the titles, abstracts and keywords. A total of 118 articles were collected and extracted.

- As the commonly cited references of the 118 articles collected (as a sample) have an important impact on the quality of our study, the database was expanded to the cited references which include the articles that are cited by the articles within our sample but are not included in the data collection (See Table 1). Over forty articles were analyzed and thirteen articles were added to our sample. The selection was restricted to only articles that covered the research topic, with a local citation score (LCS) greater than or equal to ten. In addition to the ten missed articles indexed on ISI WOS, two articles not indexed by ISI WOS were included. Thus, a total of 131 articles were compiled.

\subsection{Data Analysis Method}

There are many types of literature review such as narrative, traditional, scoping, and systematic review, among others. Systematic literature review techniques (used in this study) are slightly different and include bibliometric analysis as well as content analysis. The bibliometric analysis relies on statistical analysis to measure the impact of published articles and citations (Maditati et al., 2018). Using this method, we executed a citation analysis, a citation network analysis, a co-occurrence analysis, and a co-citation analysis. The citation analysis relies on the article or author being cited by other scientific productions. The citation

Table 1. Cited References added to the initial sample.

\begin{tabular}{cccc}
\hline Indexation & Article & TLCS & TGCS \\
\hline & Kang et al., 2010 & 42 & 117 \\
& Lee \& Park, 2009 et al., 2013 & 35 & 166 \\
& de Grosbois, 2012 & 33 & 166 \\
& Garay \& Font, 2012 & 169 \\
Meb of Science & Martinez et al., 2013 & 27 & 223 \\
& Tsai et al., 2012 & 21 & 60 \\
& Lee et al., 2013 & 16 & 103 \\
\hline EMERALD INSIGHT & Miller, 2001 & 17 & 63 \\
\hline & Levy \& Park, 2011 & 14 & 13 \\
\hline
\end{tabular}


network analysis systematically evaluates the interconnectivity of research in a particular field (Bruner et al., 2013; Moore et al., 2005). The co-occurrence analysis (number of times a paired data within a sample is repeated) was carried out through a keyword network analysis. The three steps above were coupled with a co-citation analysis to create an analytical overview. The co-citation analysis provides the citations of two papers simultaneously by a further article (Small, 1973).

The co-citation analysis was combined with content analysis, for systemically assessing the literature (Rodrigues \& Mendes, 2018). Content analysis is the result of an intersection between qualitative and quantitative evaluation (Duriau et al., 2007), and it examines and discovers underlying themes based on the associations of co-occurrences and co-absences keywords (Ronda-Pupo \& Guerras-Martin, 2012). We opted for VOSviewer software as a visual tool and HistCite software to process the data. Table 2 clarifies the main research and software terms.

\section{Results}

\subsection{Descriptive Analysis}

\subsubsection{Influential Journals}

The analysis of the journal outlets was represented in three different categories according to the number of publications of CSR in the tourism industry, the number of citations within our collection (Table 3 ) and the number of citations in the entire ISI WOS database (Figure 3).

As given in Table 3, the most productive (PCSRT) and impactful journals (TLCS) are International Journal of Contemporary Hospitality Management (IJCHM), International Journal of Hospitality Management (IJHM), Tourism Management (TM), Journal of Hospitality and Tourism Management (JHTM), Asia Pacific Journal of Tourism Research (APJTR), and Journal of Travel Research (JTR). The journals with the most publications and citations belong to two domains-tourism and hospitality management. Even though CSR is an

Table 2. Main methodological terms.

\begin{tabular}{ll}
\hline Terms & Explanation \\
\hline HistCite & A software tool for visualizing the results of literature searches in ISI WOS. \\
VOSviewer & A software tool for forming, visualizing, and exploring maps (accepts ISI WOS \& SCOPUS data). \\
PCSRT & Number of publications/articles on CSR and Tourism in our bibliometric research. \\
TLCS & Total Local Citations Score is the number of times a paper is cited by other papers within the sample (131). \\
TLCS/t & Total Global Citations Score is the number of times a paper is cited by other papers in the whole WoS database. \\
TGCS & Total Global Citations Score per year is the average global citations obtained each year. \\
TGCS/t &
\end{tabular}


Table 3. Leading journals.

\begin{tabular}{cccccc}
\hline Rank & Name of journal 1 & PCSRT & Name of journal 2 & TLCS & TLCS/t \\
\hline 1 & IJCHM & 14 & IJHM & 161 & 17.20 \\
2 & IJHM & 12 & TM & 100 & 14.13 \\
3 & JST & 11 & TMP & 41 & 5.50 \\
4 & TM & 10 & IJCHM & 36 & 5.24 \\
5 & SUST & 9 & ATR & 10 & 3.33 \\
6 & TE & 7 & JHTM & 18 & 2.90 \\
7 & JHTM & 5 & JTR & 25 & 2.78 \\
8 & APJTR & 4 & JTTM & 11 & 1.82 \\
9 & CIT & 4 & APJTR & 17 & 1.71 \\
10 & JTR & 4 & JHTR & 12 & 1.50 \\
\hline
\end{tabular}

Note: The table lists the ten leading journals in the literature of CSR in the tourism sector. $1=$ Rank of journals based on PCSRT. 2 = Rank of journals based on TLCS \& TLCS/t. For details about PCSRT, TLCS, TLCS/t, see Table 2. Journal Name and Abbreviation: International Journal of Contemporary Hospitality Management (IJCHM); International Journal of Hospitality Management (IJHM); Journal of Sustainable Tourism(JST); Tourism Management(TM); Sustainability (SUST); Tourism Economics (TE); Journal of Hospitality and Tourism Management (JHTM); Asia Pacific Journal of Tourism Research (APJTR); Current Issues in Tourism (CIT); Journal of Travel Research (JTR); Tourism Management Perspectives (TMP); Annals of Tourism Research (ATR); Current Issues in Tourism (CIT); Journal of Travel \& Tourism Marketing (JTTM); Journal of Hospitality \& Tourism Research (JHTR).

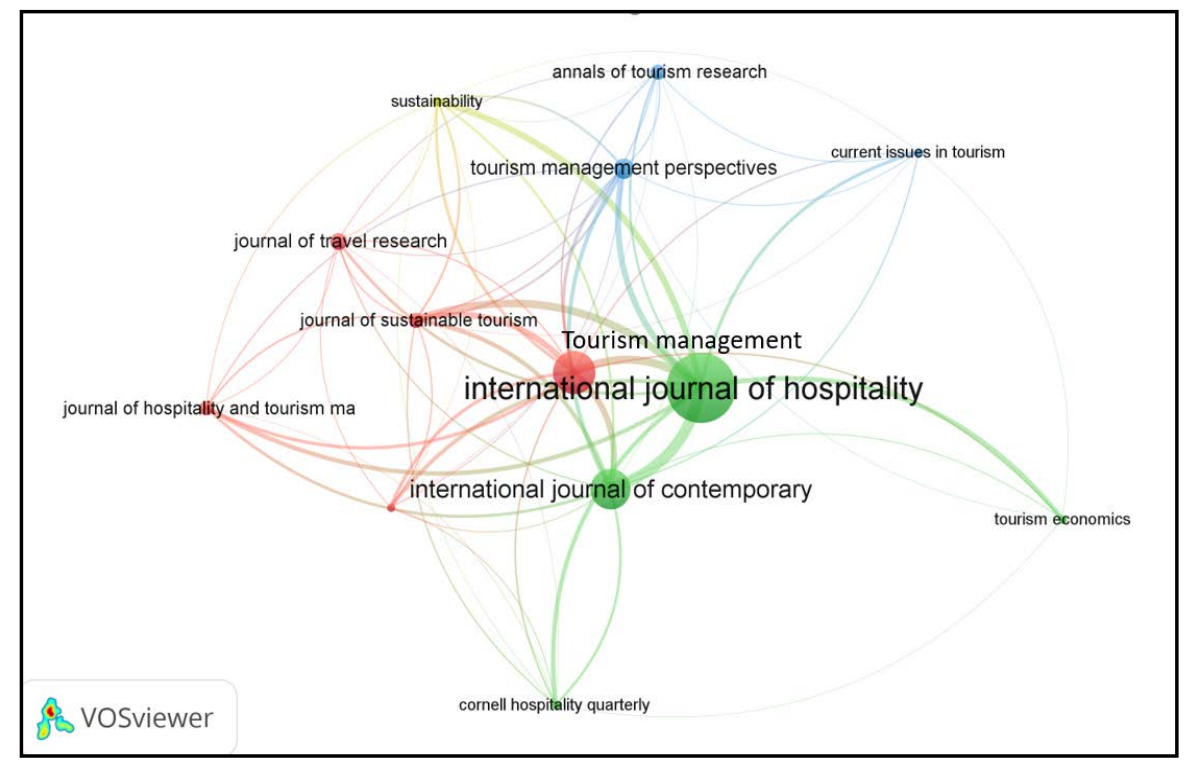

Figure 3. Citation network of journals.

interdisciplinary field, only one journal in the field of sustainability belongs to the category of the most productive journals. Furthermore, only APJTR among all 48 journals available, refers to a country or continent, and hence shows the prominence of research on CSR in the Asian tourism industry.

To scrutinize the journals further, a citation network of journals is presented in Figure 3. It shows that the greater the node, the higher the global citation of 
the journal. However, the five most cited journals in all the databases (in order) are: IJHM (39\%), TM (16.2\%), IJCHM (14.2\%), TMP (4.2\%), and JTR (3\%). The figure also shows the connection (represented in the lines) between the citing articles and the journal cited.

\subsubsection{Influential Authors and Related Aspects}

Figure 4 summarizes several key findings of output based on the bibliometric data "Authors".

Table 4 reports the top ten articles based on TGCS, TLCS and the number of publications by author. In both rankings, the same articles were cited regularly, in the two categories. Also, more than $50 \%$ of the top ranked articles come from the IJHM. As shown earlier in Figure 1, the top ten most influential articles were published between 2007 and 2013.

Our findings highlight two main researchers from the USA and UK with several articles greater than or equal to five published. Lee Seoki (six publications) is an assistant professor at the Hospitality Management School at Temple University in the USA and serves as a treasurer for the Association of Hospitality Financial Management Educators (AHFME). Font Xavier (five publications) is a professor of Sustainability Marketing at the School of Hospitality and Tourism

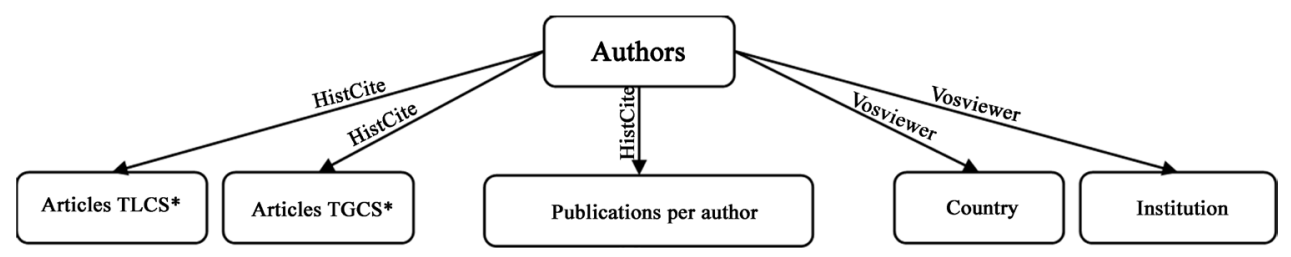

Note: For more details about LCS and GCS see Table 2.

Figure 4. Authors and related aspects.

Table 4. Influential authors and articles.

\begin{tabular}{ccccccc}
\hline & \multicolumn{2}{c}{ Influential Articles 1 } & Influential Articles 2 & \multicolumn{2}{c}{ Publications per author } \\
\cline { 2 - 7 } Rank & Author \& Year & TGCS & Author \& Year & TLCS & Author & $\begin{array}{c}\text { No of } \\
\text { Publications }\end{array}$ \\
\hline 1 & Holcomb et al., 2007 & 360 & Kang et al., 2010 & 42 & Lee S & 6 \\
2 & Kang et al., 2010 & 231 & Henderson, 2007 & 38 & Font X & 5 \\
3 & Inoue \& Lee, 2011 & 228 & Holcomb et al., 2007 & 37 & del Bosque IR & 4 \\
4 & Martinez et al., 2013 & 223 & Inoue \& Lee, 2011 & 35 & Martinez P & 4 \\
5 & Henderson, 2007 & 193 & Coles et al., 2013 & 35 & Bogan E & 3 \\
6 & Garay \& Font, 2012 & 169 & Lee \& Park, 2009 & 33 & Bonilla-Priego MJ & 3 \\
7 & Lee \& Park, 2009 & 166 & de Grosbois, 2012 & 27 & Dedeoglu BB & 3 \\
8 & de Grosbois, 2012 & 166 & Garay \& Font, 2012 & 21 & Horng JS & 3 \\
9 & Font et al., 2012 & 122 & Font et al., 2012 & 19 & Hsu H & 3 \\
10 & Coles et al., 2013 & 117 & Nicolau, 2008 & 18 & Kang KH & 3 \\
\hline
\end{tabular}

Note: The table lists the ten leading articles in the literature of CSR in the tourism sector. $1=$ Rank of articles based on TGCS. 2 = Rank of articles based on TLCS. For details about TGCS and TLCS, see Table 2. 
Management at the University of Surrey in the UK. He has conducted numerous trainings and assisted over 2000 organizations in communicating sustainability.

Figure 5 reveals the author's countries of origin based on the global citations, and Figure 6 presents the author's countries of origin based on the publication number. The four highly cited and most productive regions are: USA, China,

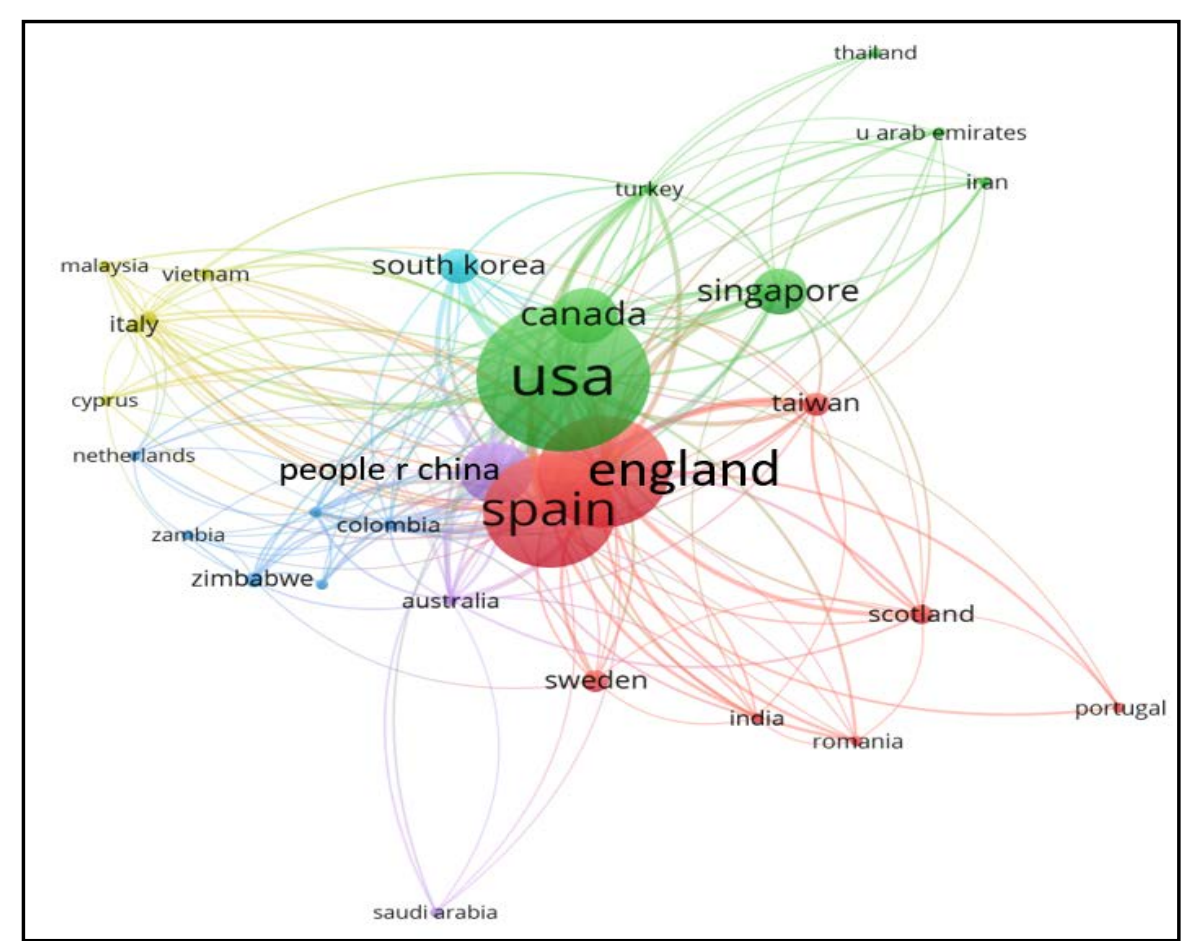

Figure 5. Citation network of author's countries.

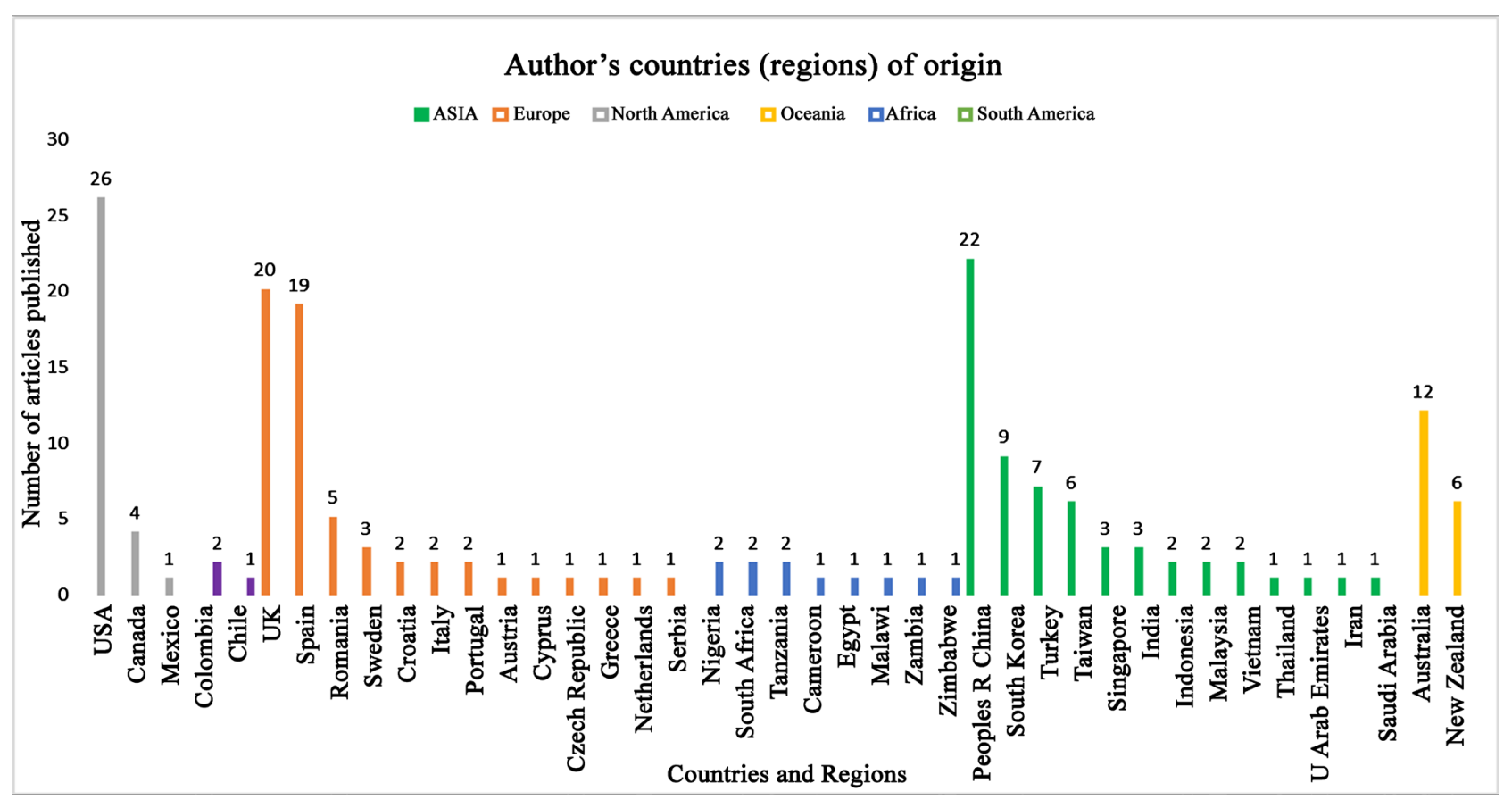

Figure 6. Author's countries (regions) of origin. 
Spain, and UK. This is understandable given the importance of the tourism industry in these regions. According to a report published by the World Tourism Organization in 2018, the four regions topped the list of the world's most visited and tourism revenue accounts for a significant share of the GDP.

Asia is the first continent to produce large amounts of literature on the topic. This can be explained by the fact that many countries in this geographical area, including China, instituted a corporate law for companies requiring them to undertake CSR. The tourism industry in the USA represents $2.8 \%$ of GDP, which makes it the top country in the world in terms of metrics (UNWTO, 2020). Sustainable tourism is one of their focuses and even though CSR is not obligatory, it is viewed by most corporations as "a must" to comply with internal norms and meet consumer expectations.

Similarly, the contribution to the literature by Spain, the second most visited country in the globe, is clear. However, some environmental and social responsibility issues must be considered following the overdevelopment of the resorts and facilities in coastal areas. The United Kingdom (UK) considers the sector as the fastest growing in terms of employment and has different types of tourism, including ecotourism.

Our result presents a new light on Singapore, which, with only three articles, has a high citation score of 212. This is owing to the publication of Henderson's article in 2007 with up to $90 \%$ total global citations. Similarly, Canada has four articles and 276 total global citations, including more than $70 \%$ coming just from Grosbois' publication in 2012.

Figure 7 reveals the universities with the most citations globally. The three universities that received the most citations are: Temple University, University of Cantabria and Leeds Beckett University. The first reputable university "Temple University" located in Philadelphia is ranked 103 in the 2021 edition of Best

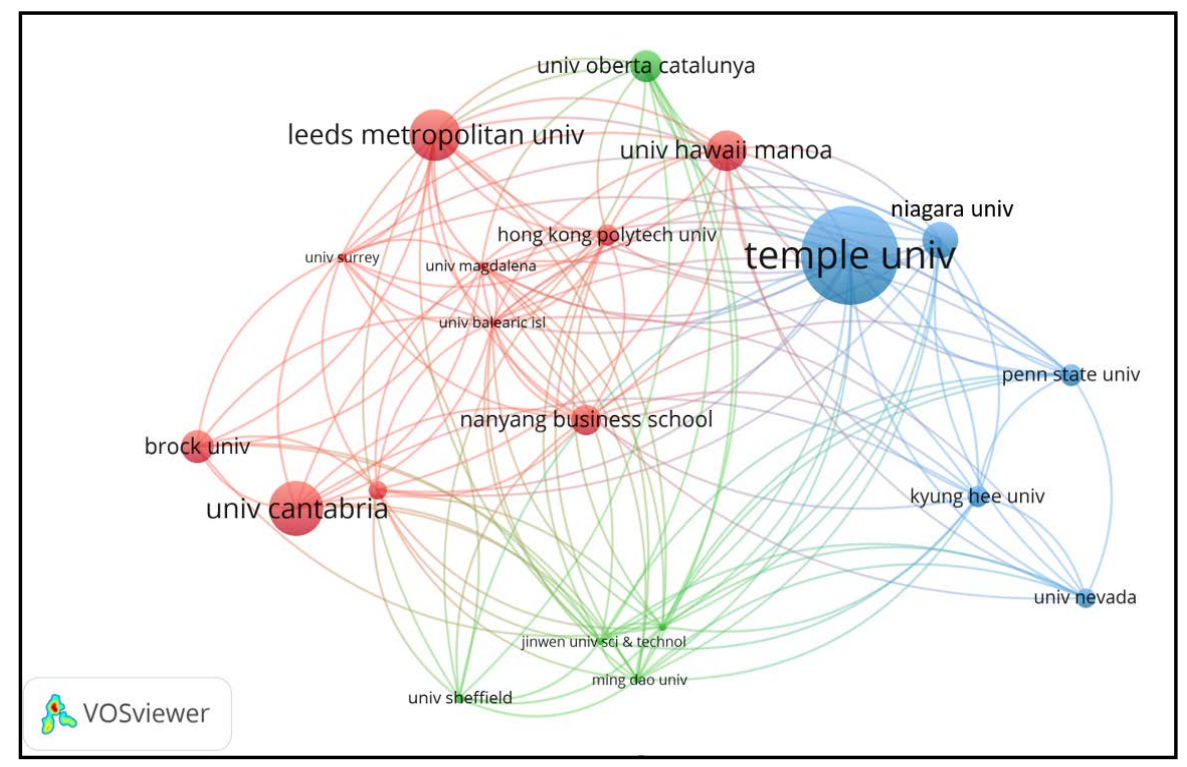

Figure 7. Citation network of author's institution. 
Colleges is National Universities of USA. The "University of Cantabria", the second most cited university, have been awarded as 'International Excellence Campus' and was ranked the ninth Spanish university to receive that award. The third most cited university is "Leeds Beckett University" in UK is listed 801 in World University Rankings by Times Higher Education and has a worldwide reputation.

\subsection{Keywords Network Analysis}

A co-occurrence analysis was deemed appropriate to identify connections between the most important keywords related to CSR in the tourism industry. This method consists of showing the frequency of keywords along with our research topic (Figure 8). We conducted this analysis using VOSviewer software for all keywords including author keywords and keywords plus ${ }^{1}$. Using three main approaches, the following interesting facts were revealed: The customer-oriented approach using repetition of keywords such as customer loyalty, consumers, and perceptions; the stakeholder-oriented approach that considers keywords such as employees, consumers and stakeholder theory; and finally, the performance-oriented approach, which considers keywords such as firm's performance, financial performance and reputation.

\subsection{Cluster Analysis}

Based on the bibliometric co-citation analysis and content analysis, four research

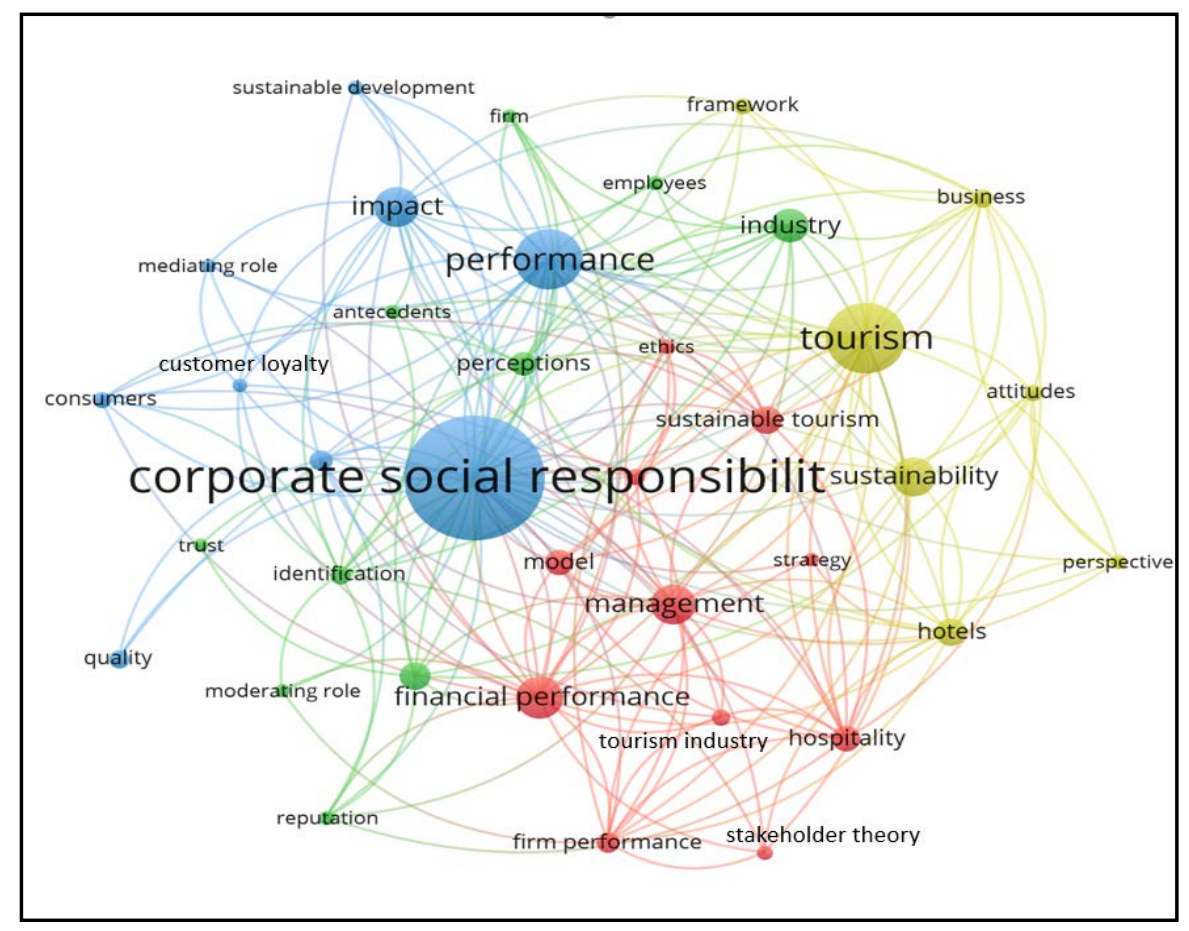

Figure 8. Citation network among keywords network analysis.

${ }^{1}$ A feature unique to WOS and consists of words that often occur in the titles of an article's cited references. 
clusters were identified. The "graph maker" tool of HistCite allows us to create a citation map that reveals the way articles refer or build on to each other (Figure 9).

The analysis was limited to only the leading papers that have at least a score of ten local citations (LCS 10). The systematic result of the bibliometric tool produced a mapping of 19 most cited articles in the literature. However, as explained earlier in the data collection method, the database was expanded to the commonly cited references (Table 1). Even though three cited references were not generated automatically in the citation mapping, they were included in the content analysis to better understand and interpret the research clusters. This resulted in a co-citation analysis of 22 articles. A traditional detailed content analysis was conducted, and articles were clustered based on their main subject and equivalence of themes. The articles were then classified into four distinct clusters: CSR and financial performance; CSR practices, drivers and inhibitors; reporting/communication of CSR; and CSR and stakeholders' behavior.

\subsubsection{Cluster 1: CSR and Financial Performance}

This first research stream is based on the impact of CSR on financial performance and the nature of the relationship that connects them. Nicolau (2008) studied the relationship between CSR actions and their market value. The results

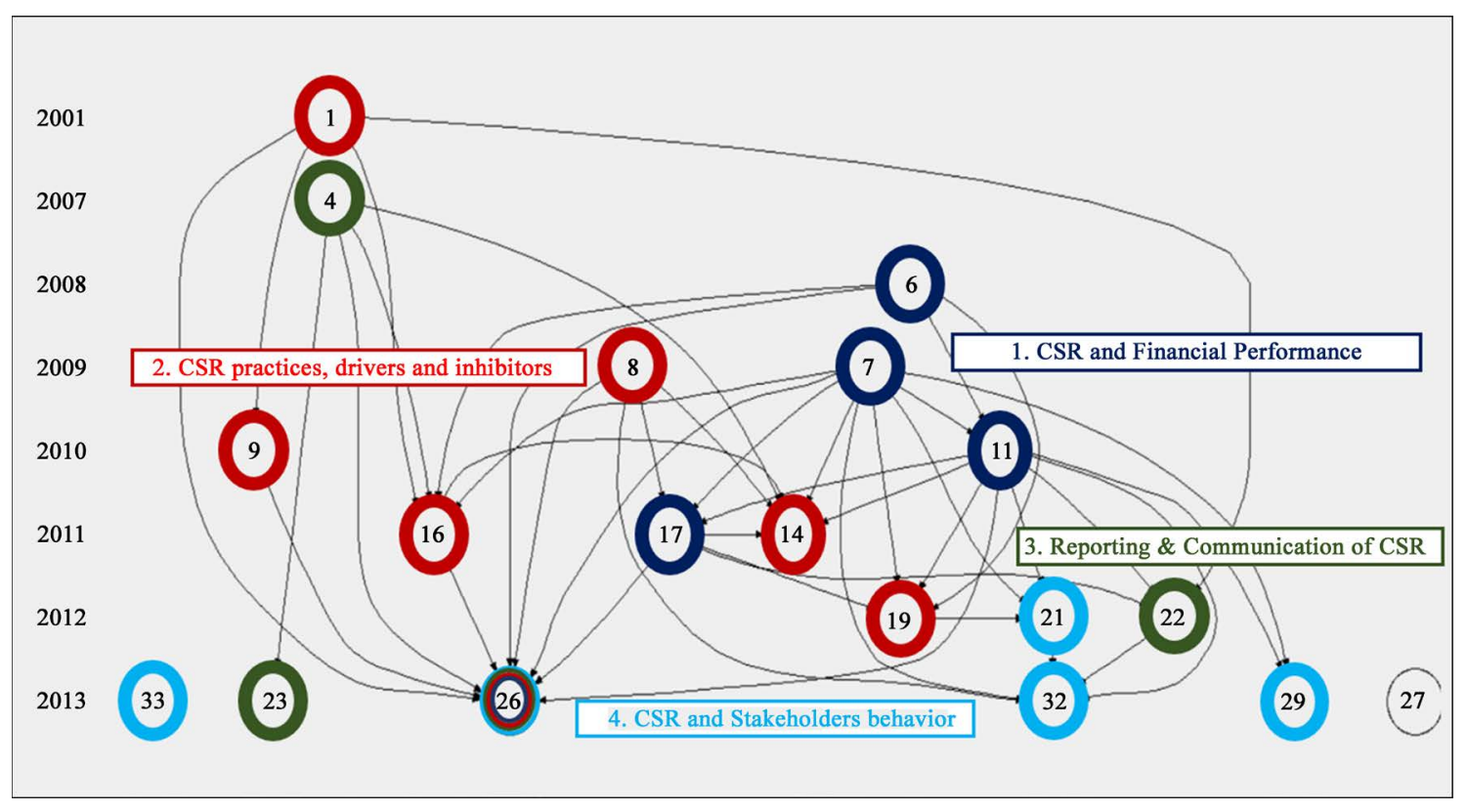

Note: Cluster 1: CSR \& Financial performance (Node. Article) 6. Nicolau (2008); 7. Lee \& Park (2009); 11. Kang et al. (2010); 17. Inoue \& Lee (2011). Cluster 2: CSR practices, drivers, and inhibitors (Node. Article) 1. Miller (2001); 8. McGehee et al. (2009); 9. Dodds and Kuehnel (2010); 14. Levy and Park (2011); 16. Sheldon \& Park (2011); 19. Garay \& Font (2012); Cluster 3: Reporting \& Communication of CSR (Node. Article) 4. Bohdanowicz (2007); 22. Font et al. (2012); 23. Nyahunzvi (2013) (+ Articles not generated in the mapping but analyzed in the content analysis: 2. Holcomb et al. (2007); 20. de Grosbois (2012). Cluster 4: CSR and Stakeholders behavior (Node. Article) 21. Tsai et al. (2012); 29. Lee et al. (2013); 32. Kucukusta et al. (2013) 33. Martinez \& del Bosque (2013). All Clusters (Node. Article) 26. Coles et al. (2013). No Clusters (Node. Article) 27. Martinez et al. (2013), (+ Article not generated in the mapping but analyzed in the content analysis: 3. Henderson (2007).

Figure 9. Citation mapping of the leading articles on CSR in the tourism industry. 
stated a positive influence on tourism firms' outcome. The event-study analysis showed that CSR creates a good environment that positively enhances consumers' perceived value towards the firm. Hence, acting socially responsible outside the business arena corresponds to obtaining economic profits.

Lee \& Park (2009) explored the relationship between CSR and short-term performance as well as long-term performance (firm value) for hotels and casinos. The findings suggest that hotels should strategically increase CSR investments, as there is a simultaneous and positive relationship with financial performance. In contrast, casinos need to carefully examine CSR-related decisions as there is no simultaneous or significant impact on financial performance. According to the authors, this is due to the nature of the casino industry, which is perceived as socially irresponsible, no matter how much they invest in CSR activities. In addition to the hotels and casinos, the restaurant and airline industries were also examined by Kang et al. (2010). The study discloses a favorable effect of positive socially responsible practices and no considerable effect of the negative socially responsible practices. Therefore, there is no significant effect of positive or negative CSR on short-term performance.

However, the research revealed a negative effect of positive socially responsible practices and no considerable impact of negative socially responsible practices for profitability in the airline industry. Negative socially responsible practices have a negative effect on long-term performance. Hence, it is suggested to reduce socially irresponsible practices (negative CSR) instead of increasing positive socially responsible practices. The study confirms the findings of Lee \& Park (2009) for the casino industry stating that no correlation occurs between CSR and financial performance.

Seeking to find which dimensions of CSR activities would improve the company's financial performance, Inoue \& Lee (2011) performed a study across four tourism sub-sectors. They found that the socially responsible investments are better maximized by developing the community and product dimensions instead of employee relations in the hotel and restaurant sector. This improves firm value and profitability. In contrast, the airline sector may emphasis their CSR investments on employee and product dimensions for firm value. Lastly, as mentioned above, the casino sector might better off reducing their socially responsible investments in all dimensions, as financial performance is not affected in any way.

Another perspective through which CSR impact on financial performance can be explored, is by analyzing the reasons and nature of the relationship between the two constructs. A study on small and medium-sized accommodation enterprises was performed by Garay \& Font (2012) and indicated that altruism is the major reason for being socially responsible even though competition is an essential motivating factor. The economic (cost reduction) and competitive (image differentiation) reasons justify the need for sustainability. However, beyond the eco-savings benefits, social and economic actions are as improving financial 
performance.

\subsubsection{Cluster 2: CSR Practices, Drivers, and Inhibitors}

A cluster of articles deals with socially responsible activities, drivers and inhibitors. First, Miller (2001) wanted to determine the factors that encouraged or discouraged tour operators to be more responsible. He identified the lack of control, the lack of financing, and the issue of pricing, as the main obstacles. As reported, these reasons prevented small companies from taking socially responsible proactive steps, as tour operators had minimal or no control over the destination and the prices offered by larger tour operators (which resulted in lower profit). By contrast, larger tour operators lacked problem awareness over the destinations. Overall, the tour operators operated only to meet minimum legal standards.

McGehee et al. (2009) examined corporate giving in the U.S. lodging sector. It was found that the more the income or invoicing level (room rates, positions on the chain scale, locations), higher the participation in philanthropic actions. Lastly, CSR decision was reported as a top-down process. To understand the awareness level and participation of CSR practices, Dodds \& Kuehnel (2010) performed a study on Canadian mass tour operators. Although all operators were conscious of CSR and climate change, not more than one CSR publication was reported. Their competitive nature forced them to focus on managing their financial risks rather than considering social and environmental factors. Most of the philanthropic initiatives were building orphanages or schools.

Levy \& Park (2011) studied CSR activities and their benefits in the US lodging sector. The importance-performance analysis indicated that the leading initiatives are related to the environment and more particularly resource-efficient practices, with a focus on energy (installing energy efficient appliances), waste (recycle/reuse programs) and water management (employing linen and towel re-use programs). Hotel executives acknowledged the various advantages of their involvement in CSR practices, like cost savings, brand image and reputation.

The last study within this research stream (Sheldon \& Park, 2011) analyzes the drivers and inhibitors of socially responsible practices in the US travel sector. Most of the respondents are engaged in some sort of CSR and almost one quarter declared having a CSR manager. The most frequently mentioned CSR motivators are reputation and community-oriented issues. The most important constraints are the need for resources and understanding. Respondents favored environmental rather than sociocultural CSR projects.

\subsubsection{Cluster 3: Reporting and Communication of CSR}

One of the main contributions of CSR literature in the tourism industry is the reporting and communication of socially responsible activities. Almost all articles within this research stream used the content analysis (annual reports, websites and CSR report published) to analyze the reporting and communication of CSR, except the case study of Hilton's computerized reporting tool. Holcomb et 
al. (2007) aimed to find the level of socially responsible behavior of the top ten hotels. The most reported CSR actions are philanthropic activities with a focus on the "community" category. Diversity to stakeholders was also significantly presented. Communicating a hotel's CSR efforts in this context proves to be beneficial in discussions with potential employees (recruitment of employees) and the creation of a competitive edge (retention of employees). As conveyed by the authors, "communicating that you are doing the right thing, can show the public that you are doing good". Nevertheless, environmental category was the area most likely to be reported. Bohdanowicz (2007) analyzed the Hilton Environmental Reporting (HER) system for environmental and benchmarking reporting. The usefulness of the system, as viewed by different regions of Hilton International, is the easy access of feedback for employees, resource use, cost statistics, and other relevant information for ecological management and socially responsible disclosures.

Another important contribution to the CSR reporting is by de Grosbois (2012). He examined socially responsible practices of 150 largest hotels in the world. His work demonstrated that hotels could have a number of reasons not to provide supplementary data on CSR, such as 1) the information is considered irrelevant to their stakeholders, 2) they have not engaged in any important initiatives, and CSR reporting is used for marketing purposes, 3) the information provided would discredit them, and 4) although their CSR performance is good, they do not collect data internally. Most hotels communicate their CSR online but few of them provide thorough and complete data about the results attained through CSR implementation. Thus, stakeholders often receive a restricted image of the hotels' CSR practices as communication remains simplistic and superficial. Analysis of the websites revealed that many hotels add or replace their reporting with examples of activities carried out by individual hotels working under their brands. The industry however, would benefit from developing standardized methodologies, reporting and uniform guidelines and measures.

Font et al. (2012) studied the potential disclosure-performance gap of the CSR for ten global hotel chains. The analysis allowed us to evaluate corporate policies and their implementation in practice. It was found that there are two separate areas-to have a policy and to follow the policy.

The main disclosure-performance gaps were found in "environmental issues" and "customer engagement". Hence, to avoid being singled out for closer scrutiny, companies engaged in not disclosing information, referred to as "greenhushing", and thus run a lower risk. Otherwise they engaged in "greenwashing", which refers to communicating environmentally and socially responsible practices to improve their corporate image when in reality they do not practice these initiatives. This showed the importance of external audits. In the developing world, Zimbabwe in particular, Nyahunzvi (2013) found that CSR reporting was related to financial performance. The socially responsible practices were considered a minor issue in the hotel groups. The online CSR disclosure can be ex- 
plained by the minimal stakeholder pressure for clearer information.

\subsubsection{Cluster 4: CSR and Stakeholder Behavior}

The focus within this research stream is on the employee and customer behavior (satisfaction and loyalty) towards a company's CSR approach. Tsai et al. (2012) analyzed the employees' perception of CSR attributes and the hotels' performance on CSR attributes. It was found that the aspects "state of affairs" and "novelty" considerably influenced the employees' perception of their companies' CSR.

Many hotels considered themselves to be socially responsible whereas the perception of CSR by their employees remained ignored. To deliver the CSR's message to guests correctly, the employees need to recognize the value of their organizations' effort. Another finding is that the "community" and the "environment" were not perceived important in terms of CSR practices.

Lee et al. (2013) analyzed the influence of CSR on employees' organizational trust, job satisfaction, and customer orientation in the casino industry. Responsible Gambling (RG) was defined by Hing (2004) as a strategy to reduce the negative influence of the casino's activities on the external stakeholders. The findings showed a positive effect of legal CSR and supplementary RG on employees' trust, while obligatory RG policies have a negative impact on employees' trust. This means that employees want their casino to be recognized as legal. Another interesting finding is that the employees' trust positively impacts their satisfaction about their work and thus customer orientation.

As stated by previous studies, employees' attitudes have a direct relationship on customers' satisfaction and loyalty (Lee et al., 2013). Martinez \& del Bosque (2013) tested the variables (trust, identification, and satisfaction) that mediate the link between CSR and customer loyalty. Their model confirmed that loyalty is influenced by perceived CSR, in an indirect way, through the mediators of trust, identification, and satisfaction.

Moreover, a considerable direct impact of socially responsible practices and customer identification on customer's trust and satisfaction was confirmed. $\mathrm{Ku}$ cukusta et al. (2013) investigated the perceptions of CSR activities in the hotel industry. The authors suggested that the companies should focus on the environment, mission, and vision within their CSR programs, as they are perceived as the most important ones in improving the service and hotels' image.

\section{Future Research Questions}

For an overview of the most recent papers of CSR in the tourism industry, the leading papers that have at least a score of ten local citations (GCS10), published between 2017-2019, were identified in Table 5. The GCS was chosen because the trending articles are generally not highly ranked as they are recent and therefore the authors may obtain higher scores in the future. However, the LCS of these articles was not high hence we used GCS as the criteria. This resulted in a total of ten emerging articles that were depicted for the future research agenda. 
Table 5. Future research agenda.

\begin{tabular}{|c|c|c|}
\hline References & Classification & Future Research agenda \\
\hline 1 (Serra et al., 2018) & Consumer reactions to CSR & $\begin{array}{l}\text { - Analyze the effect of CSR on the hotel's marketing strategies (consumer purchasing } \\
\text { process or loyalty or advocacy). (1) } \\
\text { - Research on whether the customer is willing to pay more or not for hotels that are } \\
\text { socially responsible (economic, social, environmental, ethical). (1) }\end{array}$ \\
\hline 1 (Serra et al., 2018) & Consumer awareness of CSR & - Test Non-experimental research on consumer's awareness of hotel's CSR practices. (1) \\
\hline 1 (Serra et al., 2018) & $\begin{array}{l}\text { Perceptions, attitudes, and } \\
\text { reactions of stakeholders to CSR }\end{array}$ & $\begin{array}{l}\text { - Test stakeholder's (particularly local community) perceptions, attitudes, and reactions } \\
\text { on hotel industry. (1) }\end{array}$ \\
\hline 1 (Serra et al., 2018) & Segmentation studies & - Perform segmentation studies regarding various stakeholders in the hotel industry (1) \\
\hline $\begin{array}{l}1 \text { (Serra et al., 2018) } \\
2 \text { (Theodoulidis et al., } \\
2017 \text { ) }\end{array}$ & CSR on FP & $\begin{array}{l}\text { - Study the link and the nature of the relationship between CSR and profits or financial } \\
\text { performance on the hotel sector. (1) } \\
\text { - Study the influence of CSR activities on the long-term performance for the hotel } \\
\text { sector. (1) } \\
\text { - Consider others dataset than MSCI ESG owing to some of its limitations. (2) } \\
\text { - Consider other strategy dimensions in terms of moderators. (2) } \\
\text { - Add supplementary measures when defining the financial performance. (2) } \\
\text { - Broaden the scope of moderators and control variables from what have been already } \\
\text { explored in the literature. (2) }\end{array}$ \\
\hline
\end{tabular}

1 (Serra et al., 2018) CSR on employees

1 (Serra et al., 2018), Reporting and communication 3 (Ettinger et al., of CSR

2018)

4 (Su et al., 2017)

5 (Lee et al., 2018)

6 (Kim et al., 2018)

CEO narcissism as a moderato between uncertainty avoidance and CSR
- Analyze the influence of CSR on hotels' manager's motivation. (1)

- Analyze the impact of CSR on hotel's competitiveness via innovation and productivity derived from enhanced employee and manager engagement and commitment. (1)

- Explore CSR disclosure characteristics in the hotel context. (1)

- Explore the levels of information quality by hotel companies. (1)

- Analyze CSR communication at destination level for the cooperation between tourism destinations companies and the hotel industry. (1)

- Examine the impact of CSR on making electronic word of mouth (e-WOM) positive and thus the impact on consumer's behavioral intentions. (1)

- More research on CSR communication and stakeholder engagement in consumer behavior and decision-making process. (3)

- Explore the relationship between hotels and prospective guests regarding CSR online communication. (3)

- Reproduce the research using different samples of hotels. (3)

- Conduct a comparison between local, national, and international hotel chains. (3)

- Explore CSR communication on different types of hotels (private and public). (3)

- Replicate the model in other regions, countries, and cultures. (4)

- Use additional scale items and questions to measure the perceived CSR. (4)

- Expand the research to other perspectives of tourism (i.e., religious tourism). (4)

- Expand the research model to other jurisdictions and use different sampling methods as well as other pre-tests. (5)

- Extend the analysis by examining various stakeholders. (5)

- Consider the Likert scale ordinalist approach. (5)

- Examine CSR awareness of other stakeholders. (5)

- Use external rating to measure narcissism. (6)

- Expand the research in other industries (e.g. Hotels). (6)

- Consider other cultural dimensions and differencing it with migrants' culture. (6) 


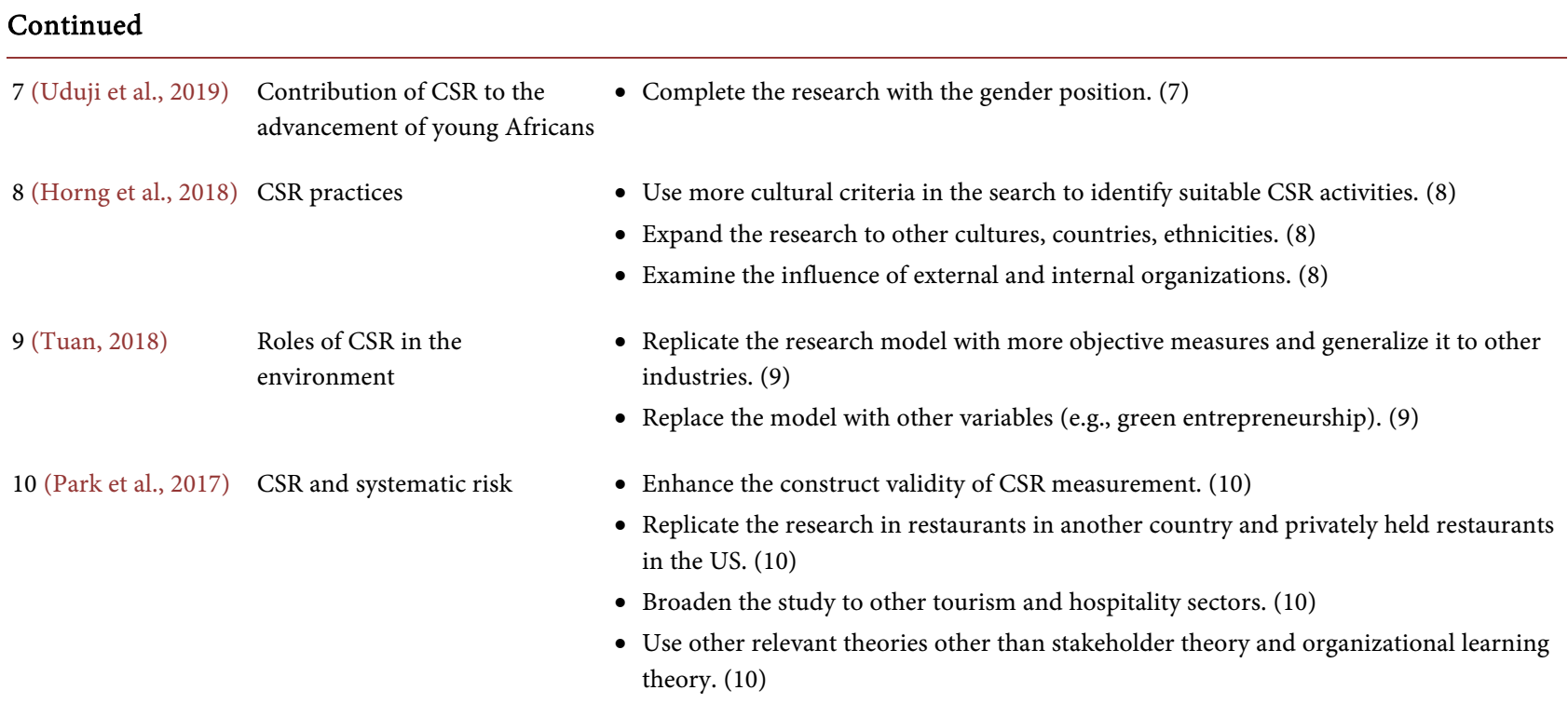

\section{Conclusion}

This research revealed the most influential aspects of the literature and addressed the future research agenda of CSR in the tourism industry by applying a bibliometric analysis. The leading journals considered were International Journal of Hospitality Management, Tourism Management, and International Journal of Contemporary Hospitality Management. The most influential articles were published between 2007-2013 with two main researchers from USA (Lee Seoki) and UK (Font Xavier), with several published articles, greater than or equal to five (according to our selection). Articles by Holcomb et al. (2007), Kang et al. (2010), Inoue et al. (2011), Martinez et al. (2013), and Henderson (2007) were found to be the most cited articles globally.

The co-occurrence analysis based on the repetition of keywords revealed three main approaches: customer-oriented approach, stakeholder-oriented approach, and performance-oriented approach. The co-citation coupled with content analysis revealed four distinct clusters: CSR and financial performance; CSR practices, drivers and inhibitors; reporting/communication of CSR; and CSR and stakeholder behavior. Finally, the future research agenda was extracted from the highest trending articles. This review shows that CSR is mainly examined in the western world; thus, there is a need to discuss the topic with regard to the developing world. Also, within the tourism industry, some sectors (accommodations and airlines for example) have attracted more academic attention than others. Hence there is a need to extend the knowledge to other subsectors and conduct more research in this area.

Future researchers may consider reviewing the related terms of CSR such as sustainable tourism, responsible tourism, and green tourism in a structured and systematic manner. This research has been undertaken in 2020 and encompasses the last 20 years. Academic researchers may undertake the same study in future, to see if there are any evolutions in clusters, for example. To deepen the under- 
standing of CSR, scholars may perform a bibliometric analysis in the tourism subsectors such as airlines and restaurants.

This study has certain limitations. The research deals only with articles retrieved from ISI WOS. Despite the highly reputed database, the articles' list remains non exhaustive. Future researchers may consider using other databases such as Scopus. The visualization tool of HistCite software is not attractive, however, future studies may attempt to use other visualization and processing software.

Although the co-citation analysis is highly systematic, it also requires some subjective elements for reviewing the literature through a content analysis. The method is criticized as being a long and slow process (Mishra \& Jagannath, 2008).

Notwithstanding the limitations, this study provides insights to both the body of literature in this field and practitioners in the tourism industry, with regard to the impact of CSR on the tourism sector.

\section{Acknowledgements}

This research was supported by Youssef Mansour, CEO of a company in the industry for his guidance in defending the current need of a meta-analysis in the topic. We are also grateful to the editor and two anonymous reviewers for their valuable comments and suggestions.

\section{Conflicts of Interest}

The authors declare no conflicts of interest regarding the publication of this paper.

\section{References}

Bohdanowicz, P. (2003). A Study of Environmental Impacts, Environmental Awareness, and Pro-Ecological Initiatives in the Hotel Industry. Stockholm: Royal Institute of Technology.

Bohdanowicz, P. (2007). A Case Study of Hilton Environmental Reporting as a Tool of Corporate Social Responsibility. Tourism Review International, 11, 115-131. https://doi.org/10.3727/154427207783948937

Bruner, M. W., Eys, M. A., Beauchamp, M. R., \& Côté, J. (2013). Examining the Origins of Team Building in Sport: A Citation Network and Genealogical Approach. Group Dynamics: Theory, Research, and Practice, 17, 30-42. https://doi.org/10.1037/a0030114

Coles, T., Fenclova, E., \& Dinan, C. (2013). Tourism and Corporate Social Responsibility: A Critical Review and Research Agenda. Tourism Management Perspectives, 6, 122-141. https://doi.org/10.1016/j.tmp.2013.02.001

de Grosbois, D. (2012). Corporate Social Responsibility Reporting by the Global Hotel Industry: Commitment, Initiatives, and Performance. International Journal of Hospitality Management, 31, 896-905. https://doi.org/10.1016/j.ijhm.2011.10.008

Dodds, R., \& Kuehnel, J. (2010). CSR among Canadian Mass Tour Operators: Good Awareness but Little Action. International Journal of Contemporary Hospitality Management, 22, 221-244. https://doi.org/10.1108/09596111011018205 
Duriau, V. J., Reger, R. K., \& Pfarrer, M. D. (2007). A Content Analysis of the Content Analysis Literature in Organization Studies: Research Themes, Data Sources, and Methodological Refinements. Organizational Research Methods, 10, 5-34. https://doi.org/10.1177/1094428106289252

Ettinger, A., Grabner-Krauter, S., \& Terlutter, R. (2018). Online CSR Communication in the Hotel Industry: Evidence from Small Hotels. International Journal of Hospitality Management, 68, 94-104. https://doi.org/10.1016/j.ijhm.2017.09.002

Font, X., Walmsley, A., Cogotti, S., McCombes, L., \& Häusler, N., (2012). Corporate Social Responsibility: The Disclosure-Performance Gap. Tourism Management, 33, 1544-1553. https://doi.org/10.1016/j.tourman.2012.02.012

Garay, L., \& Font, X. (2012). Doing Good to Do Well? Corporate Social Responsibility Reasons, Practices and Impacts in Small and Medium Accommodation Enterprises. International Journal of Hospitality Management, 31, 329-337.

https://doi.org/10.1016/j.ijhm.2011.04.013

Henderson, J. C. (2007). Corporate Social Responsibility and Tourism: Hotel Companies in Phuket, Thailand, after the Indian Ocean Tsunami. International Journal of Hospitality Management, 26, 228-239. https://doi.org/10.1016/j.ijhm.2006.02.001

Hing, N. (2004). The Efficacy of Responsible Gambling Measures in NSW Clubs: The Gamblers' Perspective. Gambling Research, 16, 32-46.

Holcomb, J. L., Upchurch, R. S., \& Okumus, F. (2007). Corporate Social Responsibility: What Are Top Hotel Companies Reporting? International Journal of Contemporary Hospitality Management, 19, 461-475. https://doi.org/10.1108/09596110710775129

Horng, J.-S., Hsu, H., \& Tsai, C.-Y. (2018). An Assessment Model of Corporate Social Responsibility Practice in the Tourism Industry. Journal of Sustainable Tourism, 26, 1085-1104. https://doi.org/10.1080/09669582.2017.1388384

Inoue, Y., \& Lee, S. (2011). Effects of Different Dimensions of Corporate Social Responsibility on Corporate Financial Performance in Tourism-Related Industries. Tourism Management, 32, 790-804. https://doi.org/10.1016/j.tourman.2010.06.019

Kang, K. H., Lee, S., \& Huh, C. (2010). Impacts of Positive and Negative Corporate Social Responsibility Activities on Company Performance in the Hospitality Industry. International Journal of Hospitality Management, 29, 72-82. https://doi.org/10.1016/j.ijhm.2009.05.006

Kim, B., Lee, S., \& Kang, K. H. (2018). The Moderating Role of CEO Narcissism on the Relationship between Uncertainty Avoidance and CSR. Tourism Management, 67, 203-213. https://doi.org/10.1016/j.tourman.2018.01.018

Kucukusta, D., Mak, A., \& Chan, X. (2013). Corporate Social Responsibility Practices in Four and Five-Star Hotels: Perspectives from Hong Kong Visitors. International Journal of Hospitality Management, 34, 19-30. https://doi.org/10.1016/j.ijhm.2013.01.010

Lee, C. K., Song, H. J., Lee, H. M., Lee, S., \& Bernhard, B. J. (2013). The Impact of CSR on Casino Employees' Organizational Trust, Job Satisfaction, and Customer Orientation: An Empirical Examination of Responsible Gambling Strategies. International Journal of Hospitality Management, 33, 406-415. https://doi.org/10.1016/j.ijhm.2012.10.011

Lee, C.-K., Kim, J., \& Kim, J. S. (2018). Impact of a Gaming Company's CSR on Residents' Perceived Benefits, Quality of Life, and Support. Tourism Management, 64, 281-290. https://doi.org/10.1016/j.tourman.2017.09.002

Lee, S., \& Park, S.-Y. (2009). Do Socially Responsible Activities Help Hotels and Casinos Achieve Their Financial Goals? International Journal of Hospitality Management, 28, 105-112. https://doi.org/10.1016/j.ijhm.2008.06.003 
Levy, S. E., \& Park, S.-Y. (2011). An Analysis of CSR Activities in the Lodging Industry. Journal of Hospitality and Tourism Management, 18, 147-154. https://doi.org/10.1375/jhtm.18.1.147

Lulewicz-Sas, A. (2017). Corporate Social Responsibility in the Light of Management Science-Bibliometric Analysis. Procedia Engineering, 182, 412-417. https://doi.org/10.1016/j.proeng.2017.03.124

Maditati, D. R., Munim, Z. H., Schramm, H.-J., \& Kummer, S. (2018). A Review of Green Supply Chain Management: From Bibliometric Analysis to a Conceptual Framework and Future Research Directions. Resources, Conservation and Recycling, 139, 150-162. https://doi.org/10.1016/j.resconrec.2018.08.004

Martinez, P., \& del Bosque, I. R. (2013). CSR and Customer Loyalty: The Roles of Trust, Customer Identification with the Company and Satisfaction. International Journal of Hospitality Management, 35, 89-99. https://doi.org/10.1016/j.ijhm.2013.05.009

Martinez, P., Perez, A., \& del Bosque, I. R. (2013). Measuring Corporate Social Responsibility in Tourism: Development and Validation of an Efficient Measurement Scale in the Hospitality Industry. Journal of Travel \& Tourism Marketing, 30, 365-385.

https://doi.org/10.1080/10548408.2013.784154

McGehee, N. G., Wattanakamolchai, S., Perdue, R. R., \& Calvert, E. O. (2009). Corporate Social Responsibility within the U.S. Lodging Industry: An exploratory Study. Journal of Hospitality \& Tourism Research, 3, 417-437. https://doi.org/10.1177/1096348009338532

Miller, G. (2001). Corporate Responsibility in the UK Tourism Industry. Tourism Management, 22, 589-598. https://doi.org/10.1016/S0261-5177(01)00034-6

Mishra, P. P., \& Jagannath, H. P. (2008). Corporate Social Responsibility in Coal Mining: A Case of Singareni Collieries Company Limited. http://www.ecoinsee.org/fbconf/Sub\%20Theme\%20C/Prajana.pdf

Moore, S., Shiell, A., Hawe, P., \& Haines, V. A. (2005). The Privileging of Communitarian Ideas: Citation Practices and the Translation of Social Capital into Public Health Research. American Journal of Public Health August, 95, 1330-1337. https://doi.org/10.2105/AJPH.2004.046094

Nicolau, J. L. (2008). Corporate Social Responsibility Worth-Creating Activities. Annals of Tourism Research, 35, 990-1006. https://doi.org/10.1016/j.annals.2008.09.003

Nova-Reyes, A., Muñoz-Leiva, F., \& Luque-Martínez, T. (2020). The Tipping Point in the Status of Socially Responsible Consumer Behavior Research? A Bibliometric Analysis. Sustainability, 12, 3141. https://doi.org/10.3390/su12083141

Nyahunzvi, D. K. (2013). CSR Reporting among Zimbabwe's Hotel Groups: A Content Analysis. International Journal of Contemporary Hospitality Management, 25, 595-613. https://doi.org/10.1108/09596111311322943

Park, S., Song, S. J., \& Lee, S. (2017). Corporate Social Responsibility and Systematic Risk of Restaurant Firms: The Moderating Role of Geographical Diversification. Tourism Management, 59, 610-620. https://doi.org/10.1016/j.tourman.2016.09.016

Rodrigues, M., \& Mendes, L. (2018). Mapping of the Literature on Social Responsibility in the Mining Industry: A Systematic Literature Review. Journal of Cleaner Production, 181, 88-101. https://doi.org/10.1016/j.jclepro.2018.01.163

Ronda-Pupo, G. A., \& Guerras-Martin, L. A. (2012). Dynamics of the Evolution of the Strategy Concept 1962-2008: A Co-Word Analysis. Strategic Management Journal, 33, 162-188. https://doi.org/10.1002/smj.948

Serra-Cantallops, A., Pena-Miranda, D. D., Ramon-Cardona, J., \& Martorell-Cunill, O. 
(2018). Progress in Research on CSR and the Hotel Industry (2006-2015). Cornell Hospitality Quarterly, 59, 15-38. https://doi.org/10.1177/1938965517719267

Sheldon, P. J., \& Park, S. Y. (2011). An Exploratory Study of Corporate Social Responsibility in the US Travel Industry. Journal of Travel Research, 50, 392-407. https://doi.org/10.1177/0047287510371230

Small, H. (1973). Co-Citation in the Scientific Literature: A New Measure of the Relationship between Two Documents. Journal of the American Society for Information Science and Technology, 24, 265-269.

https://doi.org/10.1002/asi.4630240406

Su, L. J., Swanson, S. R., Hsu, M., \& Chen, X. H. (2017). How does Perceived Corporate Social Responsibility Contribute to Green Consumer Behavior of Chinese Tourists A Hotel Context. International Journal of Contemporary Hospitality Management, 29, 3157-3176. https://doi.org/10.1108/IJCHM-10-2015-0580

Theodoulidis, B., Diaz, D., Crotto, F., \& Rancati, E. (2017). Exploring Corporate Social Responsibility and Financial Performance through Stakeholder Theory in the Tourism Industries. Tourism Management, 62, 173-188.

https://doi.org/10.1016/j.tourman.2017.03.018

Tsai, H., Tsang, N. K. F., \& Cheng, S. K. Y. (2012). Hotel Employees' Perceptions on Corporate Social Responsibility: The Case of Hong Kong. International Journal of Hospitality Management, 31, 1143-1154. https://doi.org/10.1016/j.ijhm.2012.02.002

Tuan, L. T. (2018). Activating Tourists' Citizenship Behavior for the Environment: The Roles of CSR and Frontline Employees' Citizenship Behavior for the Environment. Journal of Sustainable Tourism, 26, 1178-1203. https://doi.org/10.1080/09669582.2017.1330337

Uduji, J. I., Okolo-Obasi, E. N., \& Asongu, S. A. (2019). Does CSR Contribute to the Development of Rural Young People in Cultural Tourism of Sub-Saharan Africa? Evidence from the Niger Delta in Nigeria. Journal of Tourism and Cultural Change, 17, 725-757. https://doi.org/10.1080/14766825.2018.1502777

UNWTO, Official Website. Tourism Data Dashboard. https://www.unwto.org/unwto-tourism-dashboard 